\title{
Evaluation of steady flow torques and pressure losses in a rotary flow control valve by means of computational fluid dynamics
}

\begin{abstract}
In this paper, a novel design of a rotary hydraulic flow control valve has been presented for high flow rate fluid power systems. High flow rates in these systems account for substantial flow forces acting on the throttling elements of the valves and cause the application of mechanically sophisticated multi-staged servo valves for flow regulation. The suggested design enables utilisation of single-stage valves in power hydraulics operating at high flow rates regimes. A spool driver and auxiliary mechanisms of the proposed valve design were discussed and selection criteria were suggested. Analytical expressions for metering characteristics as well as steady flow torques have been derived. Computational fluid dynamics (CFD) analysis of steady state flow regimes was conducted to evaluate the hydraulic behaviour of the proposed valve. This study represents a special case of an independent metering concept applied to the design of power hydraulic systems with direct proportional valve control operating at flow rates above 150 litres per minute. The result gained using parametric CFD simulations predicted the induced torque and the pressure drops due to a steady flow. Magnitudes of these values prove that by minimising the number of spool's mobile metering surfaces it is possible to reduce the flow-generated forces in the new generation of hydraulic valves proposed in this study. Calculation of the flow jet angles was analytically verified by measuring the deflection of the velocity vector using flow velocity field distribution, obtained during visualisation of the results of CFD simulations. The derived calculation formulas can predict metering characteristics, values of steady flow torques and jet angles for the specified design and geometry of the suggested valve. The proposed novel structure of the flow control valve promises to attain improved controllability, reliability and efficiency of the hydraulic control units of heavy mobile machinery operating at high flow rates regimes.
\end{abstract}

\section{Keywords}

Rotary flow control valve; Computational fluid dynamics; Pressure drop; Steady flow torques; Discharge coefficient; Jet angle

\section{Highlights}

- A novel design of a rotary flow control valve driven by a stepper motor is proposed.

- The intended use of the valve in the high flow rate independent metering hydraulic system is suggested.

- Pressure drops, steady flow torques of the valve for various flow rates and orifice openings are studied by means of computational fluid dynamics.

- The discharge coefficient and flow jet angles dependencies on the orifice opening are obtained.

- A design method to decrease the flow forces without reducing the flow rate in single-staged valves is demonstrated.

\section{Introduction}

Fluid power systems are a major element in the design and development of all heavy off road, earthmoving, agricultural and construction machinery. Their contribution to the overall performance of such machines is hard to overestimate. These industrial applications require hydraulics functioning at high-pressure and high-flow rates in order to operate multiple drives of a single mobile machine such as manipulator arms, wheels, crawlers, transmission and other appliances simultaneously. These large flow rates require a substantial amount of energy to achieve and consequently result in a substantial loss of flow energy or pressure drops, which is quite common in such hydraulic systems (Merritt, 1968). These losses are usually due to viscous friction, swirls formation, sudden changes in flow direction and cross-section (Lisowski and Rajda, 2013). Considerably large flow rates also account for significant flow forces acting on the regulating elements of the control valves (Rajda and Lisowski, 2013).

In order to overcome these large resisting forces, an indirect pilot hydraulic actuation of the main sliding spool is employed. In this solution, the design of flow control valves lacks mechanical reliability due to the introduction of an additional hydraulic stage, what causes immense pressure losses, poor energy efficiency and rigorous requirements to the level of oil contamination due to sophisticated and narrow internal channelling (Filho and De Negri, 2013). Furthermore, production of such valves demands high-precision manufacturing processes. That increases the overall cost of these flow control units. Manual assembly of torque motor driven two-stage valves and their adjustment motivates investigations of alternative technologies (Plummer, 2016).

One way to reduce losses in such valves is to optimise the flow paths through them in order to lessen flow disturbances (Simic and Herakovic, 2015). One promising method to enhance the valve's performance in terms of losses, flow disturbance reduction, and simplification of the valve geometry for manufacture is to utilise specially profiled sliding spools with special geometrical features. A number of studies have shown the positive impact of smoother spool geometry, especially smoother change of diametrical sizes of a spool along its length, on the fluid's rate of momentum change, hence reducing the flow forces experienced by the spool's driver. The introduction of a compensation profile on the sliding spool's shaft diminishes the flow forces by creating a pressure drop in the downstream cavity (Amirante et al., 2007). It was proven experimentally, that geometrical optimisation of central conical surfaces on the spool shank can provide higher axial velocities at the inlet of the meter-in chamber and the outlet of the meter-out chamber of the spool, which alleviates a net flow force, and lowers dynamic overshoot in step response (Amirante et al., 2016). Cone surfaces on the 
spool's control edges and providing oil jet return back in spool's cavity on the meter-out edges enables application of direct actuation of the spool for larger nominal valve sizes (Herakovič, 2009).

Adding a supplementary parallel channel to the return line in the valve's body allows extension of the valve's operational flow range by improving the carrying capacity of the drain line without resorting to more powerful solenoids (Lisowski et al., 2013). The geometrical optimisation of flow regulating parts has a notable effect on flow forces in seat valves as well (Simic and Herakovic, 2015). Other viable ways to lessen the effect of flow forces are improvement of electromagnetic actuator's performance (Reichert, 2010), advanced regulation of spring rates of the return mechanism and geometrical optimisation of the spool's ambient parts and channels, inlet and outlet spool chambers (Abdalla et al., 2011) to make them less prone to formation of eddies, vortices and flow disturbances.

Advanced architectural approaches to design and control high-flow rate hydraulic systems are demonstrated in concepts of independent metering (Shenouda, 2006), (Choi et al., 2015) and digital hydraulics (Linjama, 2011). The former utilises separate control of flows into and from actuator's chambers. The latter consists of incremental modulation of the flows in hydraulic lines by switching on and off individual valves connected in a parallel layout. Generally, these concepts rely on two-way valve setups. These two new concepts have had limited application due to the low flow rates used to date. Nevertheless, these concepts need further advancement in order to be effectively implemented within high flow rate systems as these approaches are considered promising in performance improvement of current hydraulic systems.

Despite the vast number of design studies all looking to minimise the flow forces and static pressure losses, the application of conceptually alternative construction of throttling elements and their arrangements are still rare in current literature. The use of valves with rotary spools to solve the problems associated with large flow forces that exist in high flow rate regimes has been studied (Yu et al., 2014), (Yu et al., 2015), (Yang et al., 2010), (Wang et al., 2016). Unlike conventional designs, a rotating spool configuration creates a much smaller net area of surfaces subjected to the flow forces. So far, employment of such rotary spools industrially is restricted to manually driven on-off valves, flow dividers, and steering valves.

However, there are alternative proposals to utilise rotary valves. In a study of a three-way electronically driven hydraulic rotary valve, a detailed mathematical model of a DC-driven spool was presented (Yang et al., 2010). In the research of direct drive servo valves a single, axisymmetric spool works on a similar principle as a $4 / 3$ directional valve. It modulates proportionally and simultaneously flow areas of both meter-in and meter-out hydraulic lines of an actuator (Yu et al., 2014), (Yu et al., 2015). Spool shoulders contain several axially oriented grooves overlapping with corresponding holes on the static bush. In these structures, the single spool incorporates several fluid paths in it. That makes the structure of the spool larger for the same volume flow rate application and generates tangible pressure drops of the whole valve. A similar approach to the spool design was described in the analysis of a rotary directional control valve driven by a servo motor (Wang et al., 2016).

The introduction of switched inertia hydraulic systems provokes numerous studies of rotary fast-switching valves since the rotary arrangement of spools proved is easier to shift between open and closed states. This concept is analogous with an electric buck converter and inherent fluid inertia in hydraulic tubes to control supply pressure and flow to a motor (Pan et al., 2013). Experimental studies of switched inertia suggest fast switching can cause noise and cavitation problems (Pan et al., 2015), (Johnston and Pan, 2015).

The above-mentioned studies comprise detailed computational fluid dynamics (CFD) and experimental analyses of driving torques of spools at flow rates not exceeding 150 litres per minute (LPM). For noted design solutions, the formation of lateral or radial forces on the spool causing flexion and jamming of the spool inside the bush seems to be a common potential problem.

Minimisation of the mobile surfaces subjected to the flow forces as an approach to overcome flow forces was used in the research of an axial flow valve with rotational metering (Ansaloni et al., 2008). The proportional two-way, twoposition valve in this study has an in-line setup of regulating parts. The valve design implies inbuilt hydraulic control of the rotor's angle by means of the reducer ring sliding along helical grooves in a gap between the stator and the rotor. The suggested design might pose problems of rotor blocking and internal leakages.

There is a proposal in the study of the three-way pulse-width-modulated directional valve to harvest the fluid flow energy by embedded turbines in order to establish the spool's translational and rotary positions (Tu et al., 2012) and eventually modulate its duty ratio (Wang and Li, 2009). This design features a self-spinning turbine with rhombic slots forming throttling orifices (Wang et al., 2010), (Tu et al., 2007), (Rannow et al., 2010) and finds application in virtually variable displacement pump/motors (Tu et al., 2011).

In the current research, the emphasis was placed on the actual geometrical design of the valve's throttling elements. The aim is, by better design, to ensure slow, gradual opening/closing of the valve and flow variation to enable smoother operation and improve reliability due to simpler construction. The latter would greatly simplify manufacture and reduce the cost of these devices in the longer term. This paper both proposes and presents a new design of rotary valve and its simulated performance. The authors believe that this design is significantly different in many respects to all existing rotary valves especially in the details of the spool-sleeve assembly design.

Current research aims to develop further the concept of reduction of flow forces in high flow rate applications through the implementation of the novel design of the throttling orifice. The main impetus for this research is the detailed design investigation of a structure of the spool-sleeve assembly in order to minimise the number of spool's surfaces exposed to the flow forces and the implementation of direct control of spool position.

This study also attempts to advance the innovative concept of independent metering structurally. The research presents a strong case for that architectural approach to be the most suitable valve system in the high flow rate domain of power hydraulics. The paper addresses one of the biggest challenges in the design of fluid power systems, namely the size 
or compactness and weight of the components (Yang and Pan, 2015), which influences energy efficiency and the work cycle of mobile machines carrying power hydraulics, especially operating at high flow rates operational regimes.

\section{Proposed valve design}

The design of the developed flow control unit represents a normally closed two-position, two-way flow control valve with direct electromagnetic proportional control of the regulating spool, with a non-variable spring return mechanism to the valve's closed state. Applying terms and symbols of BS ISO 1219-1:2012, the graphical symbol for the valve was drawn, Fig. 1. All key parts are housed in a valve's casing. It supplies working fluid to the spool, collects and directs oil to the hydraulic actuator via built-in channels after throttling orifices. The valve design implies a cartridge assembly method allowing multi-valve arrangement in a single body given enough valve socket ports and matching internal channelling. Manufacturers usually favour such assembly method because such valves are easy and fast to manufacture, repair, maintain or replace in the event of a mechanical failure.

In this new proposed valve's structure, liquid enters the hollow cylindrical spool's central cavity through the end face opening, Fig. 2. Then it outflows from two specially profiled cut-outs on the outer surface of the spool's cylinder and passes through the sleeve windows. The flow rate is regulated by the opening area, which is formed by the overlap between the slots of the spool and the sleeve. The orifice area is also a function of each window profile. Consequently, the angular position of the spool in the sleeve defines the output oil's flow rate.

In order to minimise and compensate the reactive lateral, radially directed, flow forces, which lead to flexion and jamming of the cantilevered spool inside the sleeve, two slots are located on diametrically opposite sides of the spool's cylindrical surface. Such a symmetrical pattern also increases the strength of the spool by reducing the mechanical stress in the material of the part, compared to a case with a single larger orifice. The suggested spool works under torsion conditions from a steady flow torque. Its throttling cross-section in a double-orifice arrangement has higher polar (or second) moment of inertia than a single orifice design with the same throttling opening area. Additionally, a two slot configuration halves the total discharge passing through the single orifice which in turn amplifies the valve's conductance and lowers pressure drop across the valve.

The spool also incorporates two sets of circumferential grooves cut on both sides of the throttling holes. The purpose of the grooves is to lower coulomb friction in the spool-sleeve assembly and prevent silting of the spool inside the sleeve due to the small radial clearance between those parts (Merritt, 1968). The grooves also play a role of labyrinth sealing, which prevents leakages to bearing housing of the spool and flow over to the supply channel.

The profile of the sleeve's throttling holes is identical in shape to the spool's windows, but the openings on the spool and the sleeve are pointed towards each other, Fig. 3. In the current study, drop-shaped windows are used on both the spool and the sleeve. This allows a very smooth increase of the opening area when throttling begins. In turn, this ability provides the smooth start of actuation, as well as accurate velocity control of a hydraulic motor.

Location of the throttling windows on the cylindrical surfaces makes it easier to cut complex opening profiles what improves manufacturability of the flow regulating parts. The combination of the windows' shapes, nonlinear nature of the total opening area, the stroke angle and the rate of spool rotation makes the developed orifices' arrangement unique in its class. Mentioned features and flow regulation potential are currently unobtainable by any ordinary translational sliding spools. The needed flow rate can be achieved in this valve through the realisation of a specific value of the opening area, which depends on the input control signal.

The flow regulation is attained by turning the spool to a pre-set angle. The spool is controlled by a rotary electric motor. The spool angular position corresponds to a finite value of the opening area that can be calculated and established in accordance with the required metering characteristics by a controller. In this proposed new design solution, the rotational movement of the spool is accomplished via a stepper motor. This electromechanical motor has to ensure accurate positioning of the spool. It also has to maintain a specified angle even in the presence of significant disturbing fluctuating torques originated from fluid flow, inertia torques in rotary transmission and both

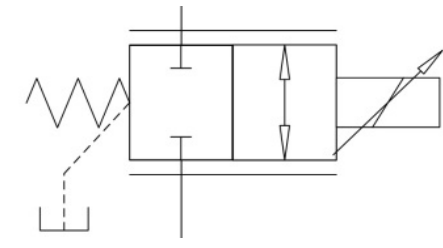

Fig. 1. Graphical, schematic representation of the developed valve.

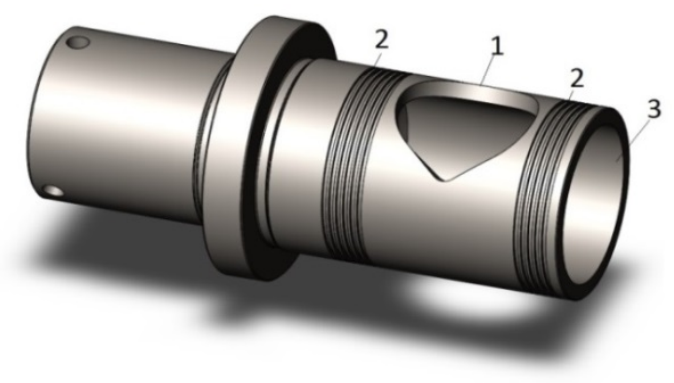

Fig. 2. The spool of the rotary control valve: 1 - orifice opening, 2 - anti-silting grooves, 3 - flow entrance to the spool's chamber.

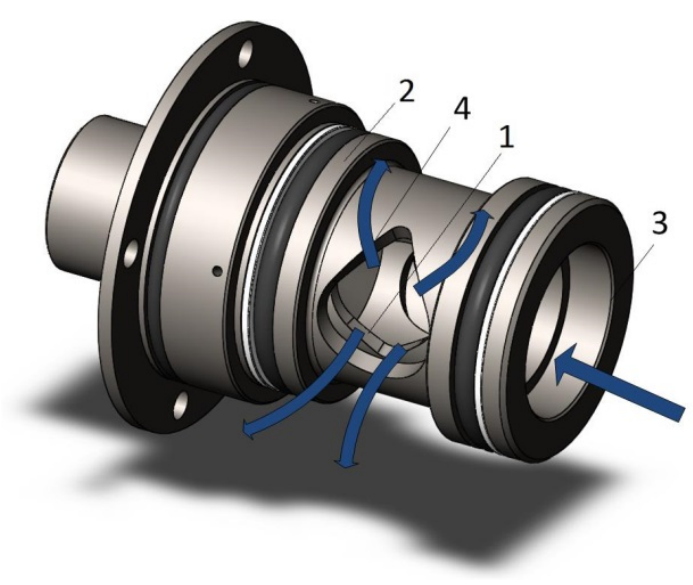

Fig. 3. The spool-sleeve assembly: 1 - the spool, 2 - the sleeve assembly, 3 - inlet to the spool's cavity (connection to the flow supply port), 4 - outlet from the valve's cavity (connection to the service port). Blue arrows indicate directions of the fluid paths inside the spool-sleeve assembly. 
mechanical and viscous friction factors. Furthermore, it has to transmit the input signal quickly and with minimal deviations from the intended values. The complex, mutable and unsteady nature of the controlled medium favours application of stepper motors with a high holding torque. Other requirements for the spool driver is its ability to withstand a high holding torque providing short settling time during state switch.

To be able to maintain the exact angular position of the spool at the steady flow regime, the driver holding torque must exceed the torques induced by the flow, viscous friction torque in the spool cavity, in the annular gap between the spool and the sleeve, and the spring torque turning the spool into the initial, closed position. For that reason, the holding torque is the main characteristic affecting selection of the stepper motor. Its detent torque determines operability of the stepper motor in the inactivated state, which corresponds to the closed state of the valve.

In conventional valves, the spool's return to a neutral state is performed with compression centring springs. This is to assure, that in the absence of an input signal on the spool actuator or its failure the spool closes all hydraulic ports of the valve. That will guarantee there is no flow between them during the no-control condition. Thus, the spring fulfils a safety function. In the rotary valve, a torsion spring is used for the same purpose. Selection of the torsion spring is based on maximum torque needed at the extreme angular positions. The spring must possess enough stiffness in order to generate a return elastic torque and be able to surmount the torques originated from oil flow, viscous and coulomb friction between contacting parts, and eventually close the valve.

Among the listed torque disturbances acting on the spool, steady flow torque is considered as the most prominent. In force terms, for sliding spools steady flow force prevails over the rest force factors and affects the selection of the spool driver mechanism and its control method.

\section{CFD simulation}

In this study parametric CFD analysis of the developed hydraulic valve is used since this method makes it possible to obtain performance characteristics of the valve theoretically and optimise them before prototype production and experimental investigation. The purpose of the CFD in this study is to establish the performance of the proposed valve design by computing metering characteristics and steady flow torques in a modelled environment.

In the case of the control valves study, the properties of interest are pressure drop imposed to the hydraulic system by the considered valve and magnitude of steady flow torques acting on the rotary spool at steady-state regimes. The latter eventually is sensed by the spool driver and affects selection criteria of the spool motor. In order to estimate these values a series of parametric simulations have been conducted. Visualisation capabilities of CFD packages help to establish fluid flow behaviour for the novel design with the original geometry of internal channels and chambers, define areas of further geometrical improvement.

According to the preceding description of the design concept, a detailed three-dimensional solid geometrical model of the valve was constructed using the SolidWorks software suite by Dassault Systems SolidWorks Corp., Waltham, Massachusetts, USA. A full three-dimensional flow model was utilised, rather

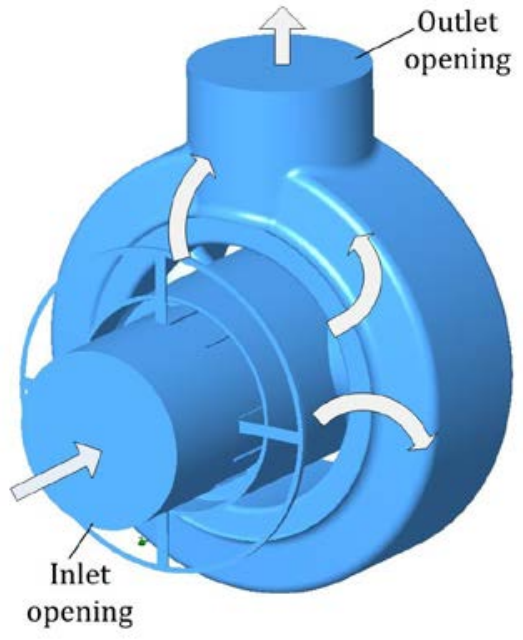

Fig. 4. Fluid subdomain, fluid flow direction.

than the simplified fluid subdomain to study a planar case of the orifice flow or axis-symmetrical flow model. This approach eliminates all the assumption made in the $2 \mathrm{~d}$ flow analysis such as uniformity of the flow paths in any adjacent planes without compromising calculation accuracy (Amirante et al., 2014).

Parametric CFD analyses have been conducted in the Flow Simulation module of SolidWorks software. Based on the depicted novel valve's geometrical model, the internal regions occupied by the oil, which is the fluid subdomain, are modelled showing the flow paths throughout the domain as seen in, Fig. 4. CFD simulations allow the visualisation of the changing flow paths corresponding to different spool's angular positions while maintaining the same overall fluid subdomain intact. At any angular position of the spool, a new fluid subdomain is extracted from the geometrical solid model altering just in the orifice area of the valve.

\section{Turbulence model}

Taking into account expected application of the developed valve, that is high pressures and high flow rates, the fluid flow inside the valve is considered as turbulent. In the Flow Simulation module, the Favre-averaged Navier-Stokes equations are used, where time-averaged effects of the flow turbulence on the flow parameters are considered. To close this system of equations, transport equations for the turbulent kinetic energy and its dissipation rate is employed, the socalled $k-\varepsilon$ model (SolidWorks, 2015). The adopted model meets accuracy and reliability requirements in the considered valve study and performs satisfactorily in solving fluid power problems (Palumbo et al., 1996).

In SolidWorks Flow Simulation the classical two-equation $k-\varepsilon$ empirical model for simulating turbulence effects in fluid flow CFD simulation (Wilcox, 2006) is used as it requires the minimum amount of additional information to calculate the flow (SolidWorks, 2013a). The modified $k-\varepsilon$ turbulence model with damping functions (Lam and Bremhorst, 1981) describes laminar, turbulent, and transitional flows of homogeneous fluids consisting of the following turbulence conservation laws (Sobachkin and Dumnov, 2013): 


$$
\begin{aligned}
& \frac{\partial \rho k}{\partial t}+\frac{\partial \rho k u_{i}}{\partial x_{i}}=\frac{\partial}{\partial x_{i}}\left(\left(\mu+\frac{\mu_{t}}{\sigma_{k}}\right) \frac{\partial k}{\partial x_{i}}\right)+\tau_{i j}^{R} \frac{\partial u_{i}}{\partial x_{j}}-\rho \varepsilon+\mu_{t} P_{B}, \\
& \frac{\partial \rho \varepsilon}{\partial t}+\frac{\partial \rho \varepsilon u_{i}}{\partial x_{i}}=\frac{\partial}{\partial x_{i}}\left(\left(\mu+\frac{\mu_{t}}{\sigma_{\varepsilon}}\right) \frac{\partial \varepsilon}{\partial x_{i}}\right)+C_{\varepsilon 1} \frac{\varepsilon}{k}\left(f_{1} \tau_{i j}^{R} \frac{\partial u_{i}}{\partial x_{j}}+C_{B} \mu_{t} P_{B}\right)-f_{2} C_{\varepsilon 2} \frac{\rho \varepsilon^{2}}{k} .
\end{aligned}
$$

Here $P_{B}$ represents the turbulent generation due to buoyancy forces and can be written as:

$$
P_{B}=-\frac{g_{i}}{\sigma_{B}} \frac{1}{\rho} \frac{\partial \rho}{\partial x_{i}^{\prime}}
$$

where $g_{i}$ is the component of gravitational acceleration in direction of $x_{i}$. The empirical $k-\varepsilon$ constants have the following typical values (SolidWorks, 2015): $\sigma_{k}=1, \sigma_{B}=0.9, \sigma_{\varepsilon}=1.3, C_{\mu}=0.09, C_{\varepsilon 1}=1.44, C_{\varepsilon 2}=1.92$ and constant $C_{B}=1$ if $P_{B}>0$, and 0 otherwise.

Following Boussinesq assumption, the Reynolds-stress tensor for Newtonian fluids has the following form:

$$
\tau_{i j}^{R}=\mu\left(\frac{\partial u_{i}}{\partial x_{j}}+\frac{\partial u_{j}}{\partial x_{i}}-\frac{2}{3} \delta_{i j} \frac{\partial u_{k}}{\partial x_{k}}\right)-\frac{2}{3} \delta_{i j} \rho k .
$$

Here $\delta_{i j}$ is the Kronecker delta function (it is equal to unity when $i=j$, and zero otherwise), $\mu$ is the dynamic viscosity coefficient, $k$ is the turbulent kinetic energy and $\mu_{t}$ is the turbulent eddy viscosity coefficient, which is determined from:

$$
\mu_{t}=f_{\mu} \frac{C_{\mu} \rho k^{2}}{\varepsilon}
$$

Here $f_{\mu}$ is a turbulent viscosity factor. It is defined by the expression

$$
\begin{gathered}
f_{\mu}=\left(1-e^{-0.0165 R_{y}}\right)^{2} \cdot\left(1+\frac{20.5}{R_{T}}\right), \\
R_{y}=\frac{\rho \sqrt{k} y}{\mu}, \\
R_{T}=\frac{\rho k^{2}}{\mu \varepsilon} .
\end{gathered}
$$

The distance from the point to the wall is $y$ and Lam and Bremhorst's damping functions are determined from

$$
\begin{aligned}
& f_{1}=1+\left(\frac{0.05}{f_{\mu}}\right)^{3}, \\
& f_{2}=1-e^{-R_{T}^{2}} .
\end{aligned}
$$

Lam and Bremhorst's damping functions $f_{\mu}, f_{1}, f_{2}$ decrease turbulent viscosity and turbulence energy and increase the turbulence dissipation rate when the Reynolds number $R_{y}$ based on the average velocity of fluctuations and distance from the wall becomes too small. When $f_{\mu}=1, f_{1}=1, f_{2}=1$ the approach obtains the original $k-\varepsilon$ model.

To simulate fluid boundary layer effects near solid bodies, solve the Navier-Stokes equations with a two-equation $k-\varepsilon$ turbulence model and evaluate skin friction in these regions a "wall function" approach (Launder and Spalding, 1974) is utilized in the Flow Simulation module. But SolidWorks Flow Simulation employs Van Driest's profiles (Driest, 1956) instead of a logarithmic profile. Additionally, a "two-scale wall functions" (2SWF) approach to describe a turbulent boundary layer and fit a fluid's boundary layer profile relative to the main flow's properties is employed (SolidWorks, 2013a).

When the number of cells across the boundary layer is sufficient (more than $\sim 10$ ) the simulation of laminar boundary layers is done via Navier-Stokes equations as part of the core flow calculation. For turbulent boundary layers proceeding from the Van Driest mixing length (Driest, 1956) SolidWorks Flow Simulations uses following dependency of the dimensionless longitudinal velocity $u^{+}$on the dimensionless wall distance $y^{+}$(SolidWorks, 2013a)

$$
u^{+}=\frac{u}{\sqrt{\frac{\tau_{w}}{\rho}}}=\int_{0}^{y^{+}} \frac{2 d \eta}{1+\sqrt{1+4 K^{2} \eta^{2}\left(1-e^{-\frac{\eta}{A_{v}}}\right)^{2}}} .
$$

Here $K=0.4504$ is the Karman constant and the Van Driest coefficient is $A_{v}=26$.

\section{Mesh generation}

Before processing, a mesh or a grid of the fluid subdomain needs to be built. The Flow Simulations module enables splitting the fluid domain into cells with adjustable resolution. Then, flow governing partial differential equations, that are the Navier-Stokes and transport equations, are solved in knots, in centres of the cells of the mesh.

The Flow Simulation solves the governing equations with a discrete numerical technique based on the finite volume (FV) discretization method as it satisfies requirements of conservation nature of the governing differential equations. The mesh cells are rectangular parallelepipeds with faces orthogonal to the specified axes of the Cartesian coordinate system. The near-boundary cells are portions of the original parallelepiped cells that are cut by the solid matter geometry boundary. Thus, the resulting near-boundary cells are polyhedrons with both axis-oriented and arbitrary oriented plane faces, partial cells. All physical and inertial parameters are referred to the mass centres of the cells within the control volume (SolidWorks, 2015). The module uses the immersed body meshing approach and yields the structured and ununiformed Cartesian mesh with an irregular distribution of mesh nodes, which results in the much faster calculation of mesh-based information required by the solver, as well as speeds up the search for data associated with neighbour cells. The Cartesian-based approach has been shown to deliver the lowest local truncation error when the Navier-Stokes equations are discretized onto the mesh, simplify navigations on the mesh, ensure robustness of the differencing scheme by the absence of secondary skewed faces (SolidWorks, 2013b). 
Automatically constructed initial meshes in SolidWorks vary in level of fineness, i.e. cell size. The built-in mesh generating algorithms enable mesh optimisation and obtaining the fine enough mesh for purposes of valves design and simulation without resorting to any further mesh refinement. However, in this study, the manual specification of the meshing parameters has been used based on the eighth level of fineness, Fig. 5. Minimum gap size and minimum wall thickness of the mesh are equal to $2.5 \mathrm{~mm}$ and $0.25 \mathrm{~mm}$ respectively. Both parameters influence the characteristic cell's size and computational domain resolution in narrow channels. Flow Simulation generates the mesh in order to have a minimum of two cells per the specified minimum gap size. The wall thickness parameter defines the refinement level of the mesh at the fine geometrical elements such as sharp edges and small protrusions (SolidWorks, 2015). Applied solutions adaptive refinement process is based on a tree structure, where the larger cells are refined into smaller daughter cells in regions with higher variables' gradients in order to minimize the spatial error arising from the discretization of the governing differential equations (SolidWorks, 2013b).

A grid independence study has been conducted for the case of $1 \mathrm{MPa}$ pressure drop between inlet and outlet openings of the valve and the spool angular position equal to $50^{\circ}$. For specified conditions, several meshes have been created differing in a number of fluid cells from 1200 up to 40000. The average value of the computed flow rate is equal to $674.35 \mathrm{LPM}$ with $3.5 \%$ fluctuations. The result of

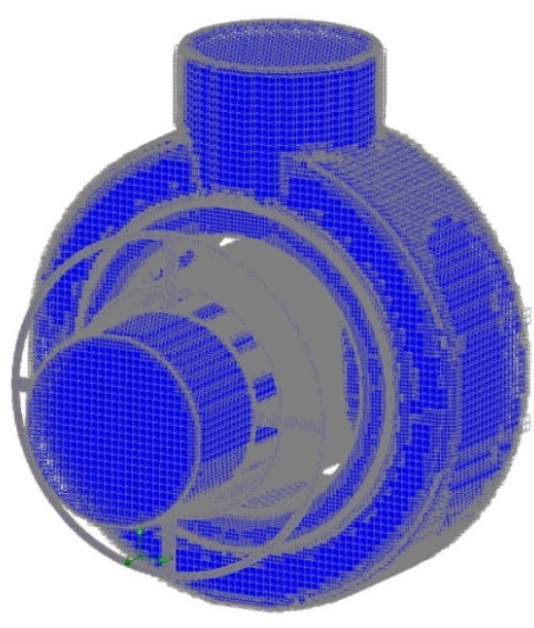

Fig. 5. Mesh of fluid subdomain. Blue cells are fluid domain, grey cells are partial cells, boundary between solid and fluid matter. the mesh independence study is shown in Fig. 6. The obtained values ensure the independence and convergence of the found solution with regard to the mesh resolutions with reasonable accuracy.

The meshing algorithm for further hydraulic boundary condition settings was selected with around 50000 fluid cells and 70000 partial cells on the bordering surfaces of solid matter. Mesh cells are not uniform in sizes across the fluid subdomain but maintain the Cartesian structure with the orthogonal faces. Areas adjacent to the throttling orifices are subjected to further automated solution adaptive refinement with the aim to optimize mesh distribution by increasing the number of fluid cells in areas with high variable changes and flow restrictions.

\section{Boundary conditions}

The specification of boundary conditions establishes a hydraulic problem in the Flow Simulation module and applies the desired magnitude of known or pre-set flow parameters for the openings. In this study, a wall roughness and slip conditions were not imposed. It is also considered that there are no leakages through external sealing lids of fluid domain.

The first objective was to gain an understanding of the hydraulic performance of the valve and to predict areas of further geometrical optimisation to reduce hydraulic pressure losses. A feature of interest was its discharge coefficient. Together with orifice area, this coefficient completes the geometrical description of the valve for the Bernoulli equation.

The second problem was to set a criterion for selection of the spool driving mechanism. Here it was desired to evaluate a jet angle of the single orifice as the determinant factor influencing the magnitude of flow torques.

In parametric simulations for both tasks, Dirichlet

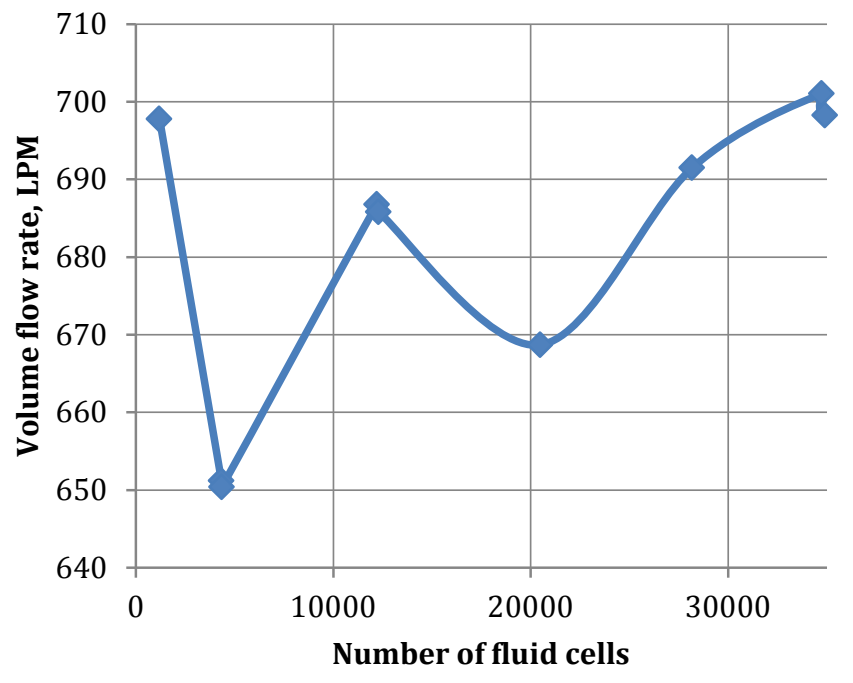

Fig. 6. Grid independence study results. boundary conditions for steady state fluid flow have been implemented. Namely, boundary conditions for the valve inlet were selected as static pressure of $0.25,0.5$ and $1 \mathrm{MPa}$; the valve outlet opening is subjected to a static pressure of $0.1 \mathrm{MPa}$. This set of spatial hydraulic boundary conditions provided varying values of the pressure difference, which dictated the volume flow rate passing through the orifice. For each variation of specified input factors, the angular position of the spool was added as a geometrical parameter varying from $10^{\circ}$ to full open state of $90^{\circ}$ with a $5^{\circ}$ step.

The oil was treated as a compressible fluid, CITGO Hydraulic Oil Grade 32. The temperature field in the fluid subdomain is non-uniform and the temperature rise has been proven to be local in small areas close to throttling edges (Ji et al., 2011). The initial fluid's temperature was taken equal to $313 \mathrm{~K}$ that corresponds to normal operational conditions of fluid power systems. For this value of oil temperature, according to manufacturer's datasheet ("Product Information. CITGO A/W Hydraulic oils," 2012), kinematic viscosity is 32.9 cSt and density is $852 \mathrm{~kg} / \mathrm{m}^{3}$. The mentioned manufactured data also provides information concerning fluid properties changes with regard to temperature variations.

\section{Goals}

The final step in the Flow Simulation module's pre-processing stage of simulations is goals specification, which are physical parameters of interest at points, on surfaces or in the specified volumes. The module initially considers any steady 
state flow problem as a time-dependent problem. The solver module iterates on an internally determined time step to seek a steady state flow field, so it is necessary to have a criterion for determining that a steady state flow field is obtained in order to stop the calculations. Convergence of the goals is considered as attaining a steady state solution as well as a condition for finishing the calculation (SolidWorks, 2015). For chosen features, convergence studies are conducted automatically for every simulation with automatically set criterion values.

Depending on a nature of the simulation, the goals vary. In the case of the analysis of the metering characteristics of the valve, the volume flow rate of the outlet opening has been selected and measured. The boundary conditions for this set of simulations are pressure differences, the orifices area, and fluid's parameters. The obtained volume flow rate completes the Bernoulli equation for calculation of the discharge coefficient of the valve with regard to the spool angular position.

Using the same set of boundary conditions, but different goals, i.e. torques on metering faces relatively to the spool axis, CFD yields all needed parameters for determining the jet angle of the orifice, both graphically through the field of the velocity vector and analytically through the mathematical formula for steady state torque derived in the following section.

The selected set of boundary conditions and the goals provides a complete description of the functionality for the designed valve structure at any hydraulic operational regime. These parameters set a basis for the further detailed development of the valve and optimisation of its geometry.

\section{Theoretical analysis}

\section{The steady-state flow torque}

In order to derive the mathematical expressions for estimation of the steady flow torques acting on the spool of the developed valve analytically, the law of conservation of fluid flow momentum is used (White, 1999). According to the law and referring to the Fig. 7 ,

$$
\overrightarrow{F_{f l}}=\dot{m}\left(\overrightarrow{v_{2}}-\overrightarrow{v_{1}}\right)
$$

where $\overrightarrow{F_{f l}}$ is the vector of the net force acting on the flow stream tube causing a change of fluid flow's direction, $\dot{m}$ is change of mass of fluid in the control volume or the mass flow, $\overrightarrow{v_{1}}, \overrightarrow{v_{2}}$ - average flow velocity vectors on the inlet and the outlet section of the control volume respectively.

According to Newton's third law, a force with the same magnitude but opposite direction acts on a structure ambient to the fluid flow. Hence, this opposite force acts on the spool, prompting the closure of the valve. The fluid density $\rho$ is taken as a constant and distributed uniformly across the fluid subdomain and the expression for the mass flow is

$$
\dot{m}=\rho Q \text {. }
$$

Radial projections of the flow force $\overrightarrow{F_{f l}}$ cancel out each other since in the proposed design there are two orifices, located on opposite sides of the spool's cylinder. Radial components do not contribute to the formation of steady flow torques as they intersect with the axis of rotation, the spool axis. Thus, the spool does not perceive them and only tangential projections of the flow force produce the flow torques. Hence, flow force acting on the single orifice can be expressed as

$$
F_{\text {fl.tan }}=\dot{m} v_{2} \sin \theta=\rho Q_{\text {single }} v_{2} \sin \theta,
$$

where $\theta$ is a jet angle or the angle of streamline's deflection due to the obstacle to the flow. In the derived equation, the orifice inlet velocity disappears, because the inlet velocity vector is directed radially. Therefore, it takes no part in the generation of the tangential flow force and the steady flow torque.

It is assumed, that the velocity profile on the spool's inlet face is uniform and total discharge $Q_{\text {total }}$ of the whole valve is split equally between two orifices, with discharge $Q_{\text {single }}$ passing through the single window, i.e.

$$
Q_{\text {total }}=2 Q_{\text {single }}
$$

According to Bernoulli relation, the output, efflux velocity of the orifice is

$$
v_{2}=C_{v} \sqrt{2 \Delta p / \rho}
$$

where velocity coefficient $C_{v}=0.98$, which accounts for pressure losses in the orifice (Lienhard, 1984) and $\Delta p$ is a pressure difference between inlet and outlet ports of the valve. Combining equations for the output velocity (5) and the flow force expression (3) multiplied by the spool external radius $R_{\text {sp.ext }}$ yields the expression for the steady state flow torque acting on the spool, i.e.

$$
T_{f l}=C_{v} Q_{\text {total }} \sqrt{2 \Delta p \rho} R_{\text {sp.ext }} \sin \theta .
$$

This expression takes into account influence of both orifices during the development of the total steady flow torque. 
Direct analytical or theoretical estimation of the jet angle on the metering edges poses numerous challenges (Amirante et al., 2006). In valves with complex geometry, jet angles are obtained based on the velocity vector field distribution from CFD simulation. Since the jet angle of the fluid is the function of spool position and does not depend on pressure difference (Lisowski et al., 2015), the arbitrary configuration of boundary conditions during CFD can be used in order to estimate the jet angle versus the spool angular position. It is noteworthy, that the jet angle in the considered rotary spool design highly depends on the location of a sink channel since it defines the direction of the fluid flow from the throttling orifices.

Rearranging equation for the flow torques relative to the jet angle yields analytical expression of the jet angle:

$$
\theta=\arcsin \left(T_{f l} /\left(C_{v} Q_{\text {total }} \sqrt{2 \Delta p \rho} R_{\text {sp.ext }}\right)\right) \text {. }
$$

Given the torque and the hydraulic parameters and the geometry of the throttling elements, the jet angle magnitude for any spool position can be evaluated analytically. Comparison with measured jet angles on velocity vector plots determines validation criterion for the derived expression. The validated jet angle function can be used further as the main descriptor of the valve's orifice.

\section{The opening area}

The Bernoulli's law describes behaviour of the flow parameters during fluid efflux from an orifice

$$
Q=C_{d} A(\varphi) \sqrt{2 \Delta p / \rho}
$$

Here the discharge coefficient $C_{d}$ is a function of the orifice shape and flow conditions (White, 1999). However, it has been shown through CFD simulations that in developed turbulent flows the discharge coefficient becomes independent of the flow conditions (Borghi et al., 1998). Thus, the orifice area $A(\varphi)$ and the discharge coefficient complete the independent geometrical description of the valve and predict the valve's performance at any operational regime of the hydraulic control system.

Given a flow regime, i.e. flow rate, pressure difference, and the opening area are all set; equation (19) can be rearranged to calculate the discharge coefficient $C_{d}$.

$$
C_{d}=\frac{Q}{A(\varphi)} \sqrt{\frac{\rho}{2 \Delta p}} .
$$

The opening area $A(\varphi)$, which is a function of the spool angular

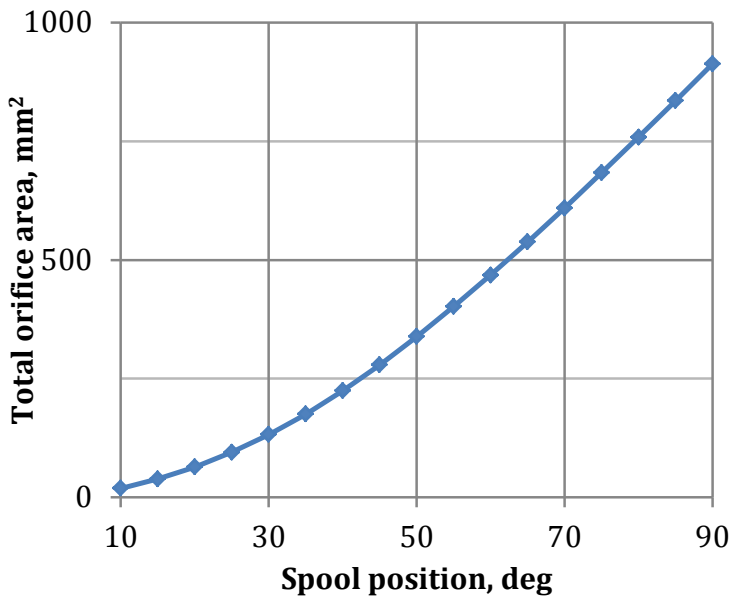

Fig. 9. The opening area of the valve. position $\varphi$, is an undetermined quantity. The remaining values in equation (20) are either taken as constant or defined through CFD computations.

Due to the specific shape of the individual profiles of the windows, the total opening area has a nonlinear dependency with regard to the spool angular position. This fact allows implementation of the desired flow rate gain during valve operation.

Easy access to the external cylindrical surfaces of the sleeve and the spool at the production stage enables cutting windows of almost any shape. This opens opportunities to implement virtually any regulation curves of the flow rate.

Selected profiles produce negative overlap at the spool's initial position, at $\varphi=0^{\circ}$, Fig. 8 a. The profiles are identical geometrically, but they are projected on cylinders of differing diameters. This creates a disparity between angles occupied by windows on the cylinders of the spool $\alpha=89.14^{\circ}$ and the sleeve $\beta=88.88^{\circ}$ measured along their circumferences in

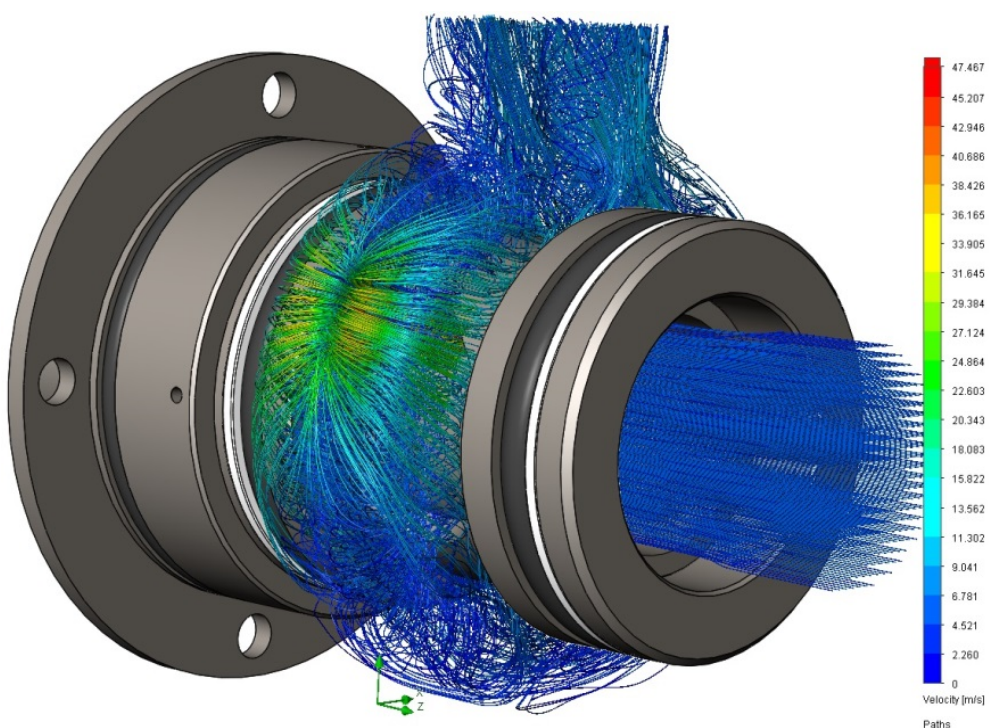

Fig. 10. Flow streamlines inside the valve at the spool position of $25^{\circ}$ and pressure difference of $1 \mathrm{MPa}$.

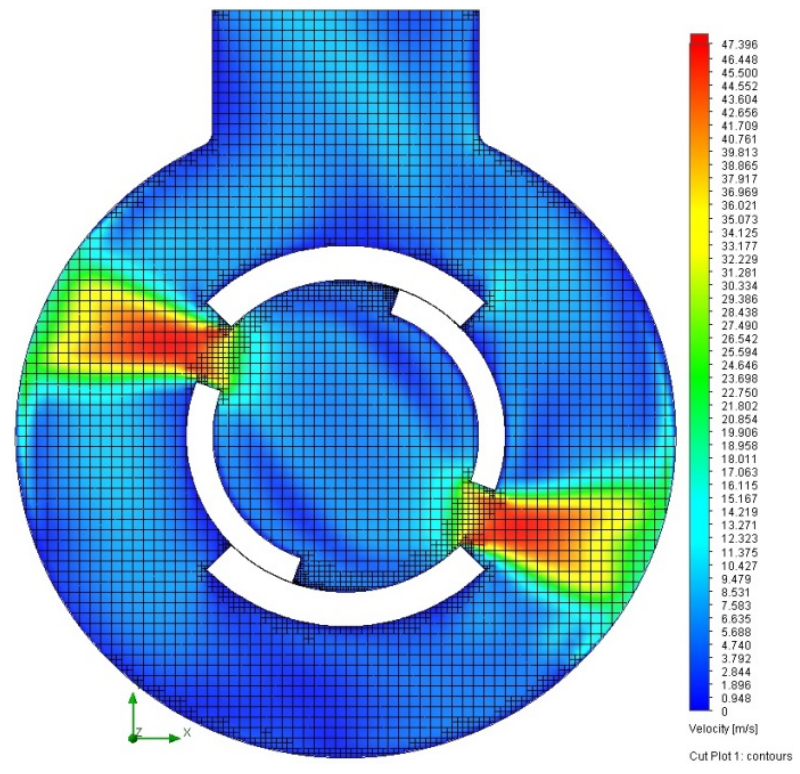

Fig. 11. Velocity field and the mesh distribution in the middle plane of the throttling windows. Spool position is $25^{\circ}$ and pressure difference is $1 \mathrm{MPa}$. 
symmetry planes of the profiles. According to these values of window angles of the parts, the overlap angle or backlash angle is

$$
\gamma=(\alpha-\beta) / 2=\left(89.14^{\circ}-88.88^{\circ}\right) / 2=0.13^{\circ} \text {. }
$$

In order to determine the relation between the single orifice area and rotational angle of the spool, swept or unrolled profiles of the windows have been used in a planar study, Fig. 8. Overlaying spool and sleeve profiles and replacing angular displacement with linear displacement, the intersection area can be assessed, which is equal to the single orifice opening. Doubling intersection area of the single orifice yields the total opening of the valve depending on the spool position, Fig. 9.

It can be seen from the graph of Fig. 9, that the rate of increase in the opening area of the valve is gradual, but not even. The smooth increase of the opening, up to $40^{\circ}$ of spool position, results in a much smoother change of actuator cylinder's speed. This slow nonlinear change in the area at the start of actuation is a special design feature of this novel valve. The dependency, beyond $40^{\circ}$ angular position of the spool, is steeper and much closer to a linear rate of opening. The maximum opening area is $912.7 \mathrm{~mm}^{2}$ at the spool position $\varphi=90^{\circ}$, which is the fully open valve state.

The developed relation offers finer regulation and better controllability of the hydraulic actuator at the low-speed regime and at the start of motion of a cylinder rod. Realisation of this shape of the opening area gain is attained by use of smooth profiles of throttling windows with small radii, where intersection begins between profiles. Smooth and continuous increase of the orifice area prevents peaks, which can lead to a hydraulic hammer effect and shocks in hydraulic cylinder motion.

\section{Results and discussion}

The results of the CFD study provide information regarding the distribution of the flow paths, Fig. 10, velocity field, Fig. 11, and velocity vector field inside the valve structure. Although the outflow is three dimensional, the plots of velocity features have been built in the middle plane of the throttling windows, which form the orifices. This choice for the middle plane for analysis is vindicated as this domain gives a better visualisation of the flow pattern at the orifice.

According to the depicted efflux model, the fluid flows radially to the throttling area inside the spool's inner cavity. This justifies the assumption taken in the theoretical analysis of the flow torques. Two jets are being formed with maximum fluid velocity inside the jets reaching values of $50 \mathrm{~m} / \mathrm{s}$ depending on the opening area and volume flow rate passing the orifices. These jets then hit the housing walls. At that point, the jet flow splits. Streamlines stick to the casing surface due to Coanda effect (Trancossi, 2011). This effect coupled with the collision of the jets with the walls, at almost right angles, results in a split of the jets.

In the plane of throttling, one portion of the flow from the single jet is guided to the valve's outlet. The other part of the jet is routed downward, to the area opposite to the sink channel. Due to the jet's separation, there are two major areas of the fluid subdomain, which are highly prone to the constitution of significant fluid circulations. These are the bottom region opposed to the sink channel and the domain of merging fluid streamlines at the sink channel. Both of these regions account for flow energy losses due to viscous friction in multiple swirls formed there. It is also noted based on the CFD visualization that areas adjoining to the sleeve metering edges close to the sink channel as well as transition domain between the metering chamber and the sink channel are prone to flow separation especially at high values of the opening area as the volume flow rate increases. The mentioned regions represent areas for further geometrical optimization to improve fluid flow trajectories by introduction of smooth fillets.

Due to vorticity in the inner cavity of the spool, there is a deviation from the assumption of equality of the volume flow rates passing through the orifices. Another contributing factor is linked with the asymmetric disposition of the orifices with regard to the sink channel on the small angular displacement of the spool. Partition of the discharge is not constant during the course of the spool opening. Up to $50^{\circ}$ of opening, the left orifice's area contains a larger domain of high fluid velocity compared to the right orifice since the left orifice is located closer to the sink channel and constitutes lower resistance to the flow. However, inequality of the flows passing through two orifices does not affect the derivation of the

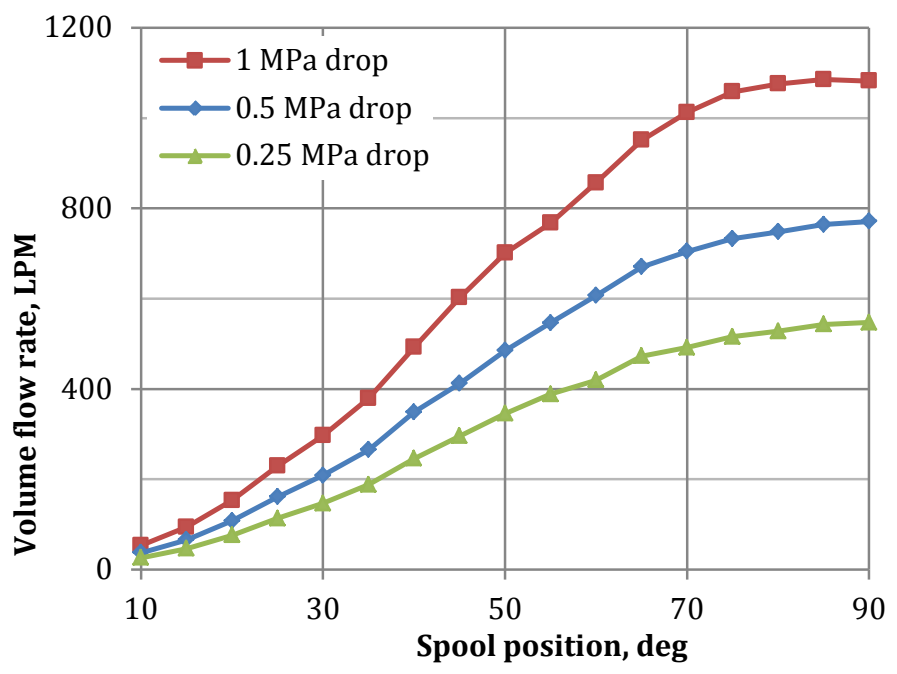

Fig. 12. Volume flow rate through the valve.

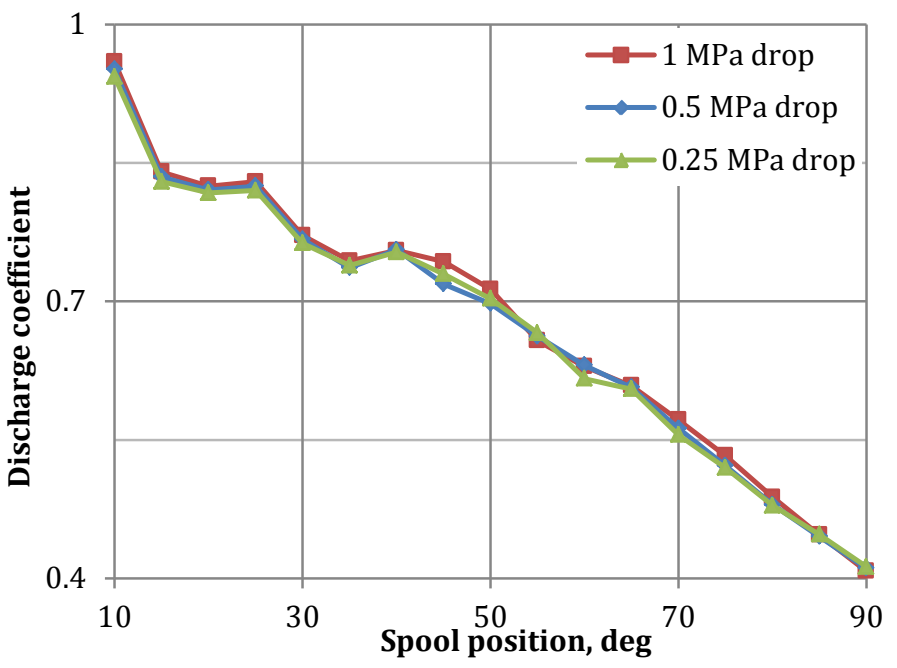

Fig. 13. Discharge coefficient of the valve. 
analytical expression of the steady flow torques. Furthermore, at the fully open state the location of the valve's orifices becomes symmetric relative to the axis of the sink channel as well as the flow model.

During the CFD simulation studies of the valve, the spool rotation angle is considered as the main parameter ranging from $0^{\circ}$ to $90^{\circ}$ with an increment of $5^{\circ}$. The pressure drop across the orifice had definite magnitudes of $0.25 \mathrm{MPa}, 0.5 \mathrm{MPa}$, and $1 \mathrm{MPa}$. The volume flow rate as a function of the spool position has been found for specified pressure drops. Interpolation plots for discrete data points of calculated flow rates can be found in Fig. 12. The discharge increases as the opening area grows. From $25^{\circ}$ and up to $65^{\circ}$ of valve's opening, volume flow rate exhibits an almost linear rise. Domains close to extreme spool positions have smoother flow rate gain. This benefits controllability of a hydraulic motor at small and maximum speed regimes.

Derived flow rate characteristics of the valve allow calculation of the discharge coefficient of the orifice for any given spool angular position, Fig. 13. For any pressure drop across the valve, computed discharge-coefficient curves coincide and decrease as the valve opens. The maximum value of the coefficient is 0.95 at $10^{\circ}$ opening, the minimal value is 0.41 at the valve's open state. With the predetermined orifice area and the discharge coefficient relation, hydraulic behaviour of the valve can be predicted for any operational regime of the hydraulic system.

In order to estimate pressure drop imposed by the valve to the hydraulic circuit it is installed in, another set of simulations has been conducted. In this case, the flow rate passing through the valve and the outlet pressure of $0.1 \mathrm{MPa}$ have been selected as the boundary conditions. Volume flow rate here alters from 100 LPM to 600 LPM with a step of 100 LPM. The measured goal is the magnitude of inlet pressure. The resultant pressure drop curves for indicated discharges decline nonlinearly, with the relation close to exponential, and do not exceed $1 \mathrm{MPa}$ at the fully open state of the valve, Fig. 14.

The calculations of steady flow torques have been performed for the same range of pressure drops and spool positions as for computations of the volume flow rate. The only difference is the set of goals. In this case, the metering faces of the spool have been selected on both orifices and the obtained data is plotted, Fig. 15. These faces are features of interest because at steady state flow the rest of the spool surfaces are cylindrical and do not contribute to the steady flow torque formation. Measurement of the torques was performed relative to the axis of the spool.

As the flow passes the throttling edges, two torques act on the spool in opposite directions: opening and closing the valve. The difference between them accounts for the total steady flow torque perceived by the spool driver. Results show that the closing torque prevails over the opening torque. This fact takes place since the metering faces adjacent to highvelocity jets are subjected to a lower pressure than the metering surfaces outside the throttling region. The steady flow torque has a dependency close to parabolic to the spool position. The maximum value of the flow torque is noted when the spool is positioned at $50^{\circ}$ or in the middle of the opening range. This domain of spool positions distinguishes itself due to the influence of both volume flow rate and deflection of the flow reaching its maximum. The largest

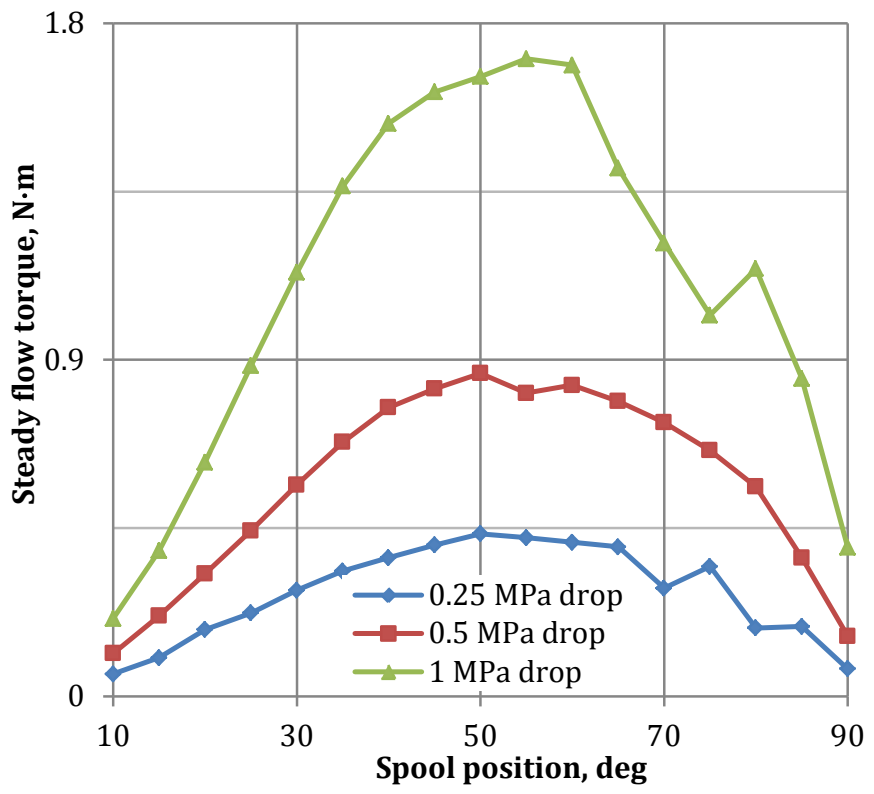

Fig. 15. Steady flow torque as a function of the spool position and the given pressure drops across the valve.

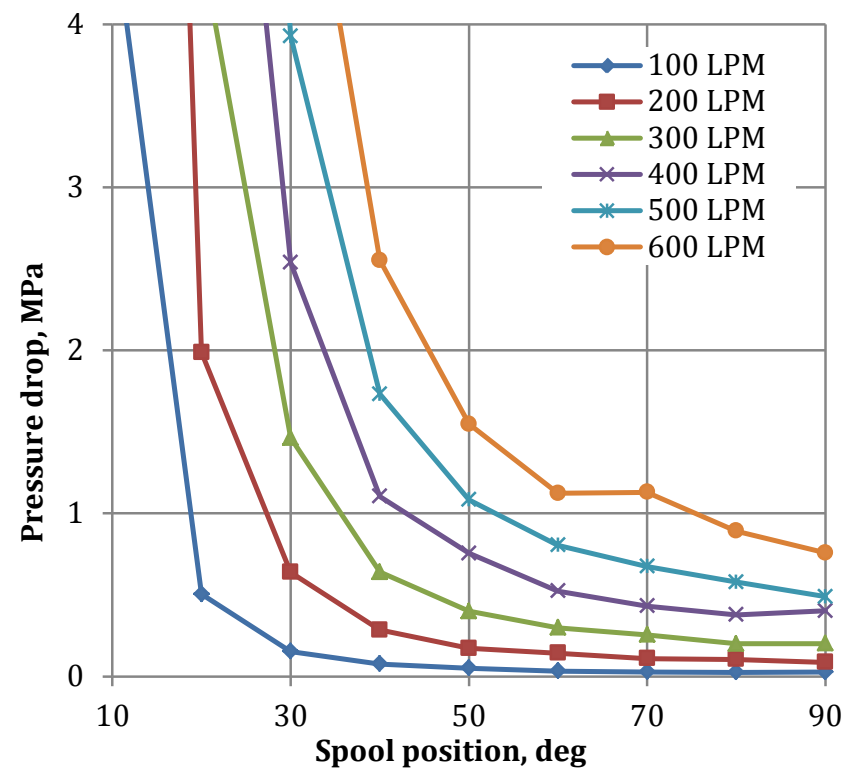

Fig. 14. Pressure drop created by the valve as a function of the spool position and volume flow rate.

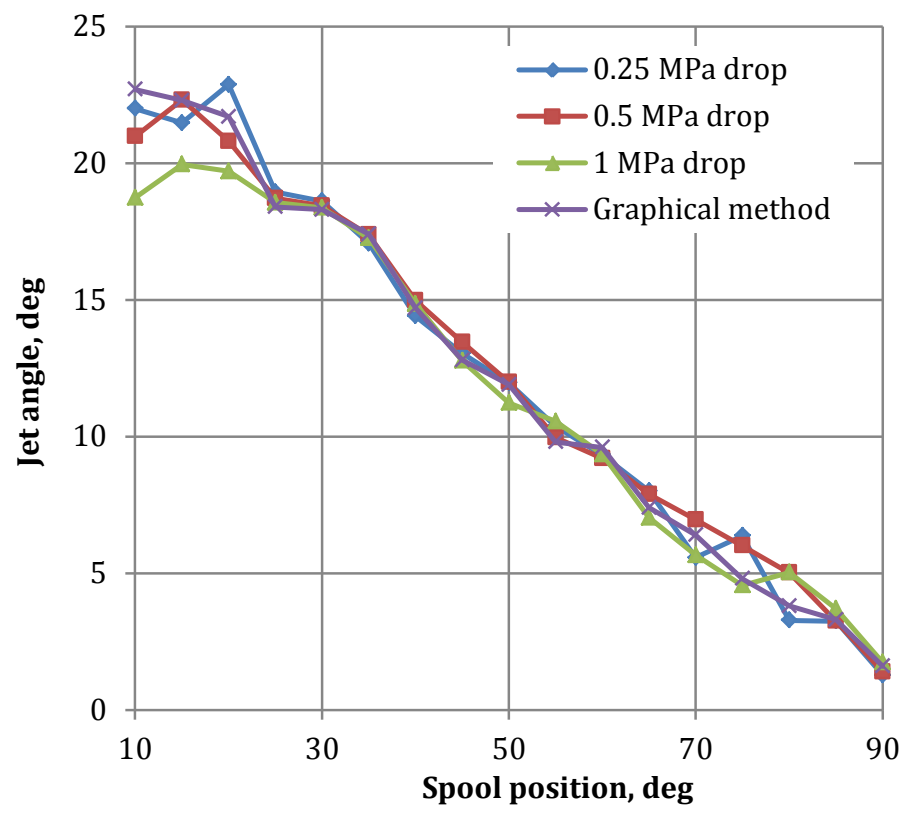

Fig. 16. Jet angle as a function of the spool position and the given pressure drops across the valve. 
steady flow torque for the $1 \mathrm{MPa}$ pressure difference across the valve does not exceed $1.8 \mathrm{Nm}$.

Based on the obtained values of flow torques it is possible to calculate the jet angle of the flow for any given spool position, according to the eq. (18). Given that the direction of diverted streamlines does not depend on flow characteristics as flow rates and pressure drops, calculated jet angle curves overlap for different pressure drops across the valve, Fig. 16. The jet angle curves vary continuously from $23^{\circ}$ at $10^{\circ}$ of the spool opening to $2^{\circ}$ at the fully open state of the valve. Independently to pre-set pressure drops, jet angle curves descend on the whole range of the spool angular position. The described relation of jet angles to spool positions applies for the chosen arrangement of the throttling elements, windows' profiles, and housing geometry. The main housing geometrical parameters affecting jet angle magnitudes are cross-section shape of the collecting channels and the location of the sink port. The influence of the pressure drop value on the discharge coefficient Fig. 13 and the jet angle Fig. 16 is negligible, which was reported in a similar study of a directional control valve by a direct numerical simulation (Posa et al., 2013).

With the use of a CFD study of flow torques, an alternative graphical method has been employed to find the jet angles, Fig. 17. The method was used in a number of studies considering jet angles evaluation in flow control valves in order to determine flow forces acting on the valve's regulating elements (Lisowski and Filo, 2016), (Lisowski et al., 2015), (Amirante et al., 2007), (Wang et al., 2016). Distribution of the velocity vectors of the flow has been extracted from the series of spool positions. For each plot of the vector field, the deflection angle of the flow has been quantified. Radial direction of the fluid flow at the orifice plane is considered as the orientation of inlet velocity. Then the orifice outlet velocity direction was drawn coinciding with velocity vectors beyond the orifice. Thus, the angle between the radial and the drawn line represents the sought orifice jet angle. Points of external sleeve circumference are taken as measurement points for directions of the outlet velocity as they are far from the flow regions directly influenced by the housing walls as well as the orifice area itself. Hence, the effect of the near-wall region of the casing is excluded.

As the opening of the valve progresses further from $75^{\circ}$, the substitution of metering edges takes place. Before the spool position of $75^{\circ}$, each orifice is created by both spool and sleeve metering edges. After this point, the sleeve edges are concealed by the spool edges and do not contribute to the formation of the orifice and throttling. This fact affects the choice of the orifice plane at a graphical estimation of the jet angles. The graphical method imposes an accuracy challenge during the evaluation of the jet angle. Namely, it appears in the selection of the measurement points and setting the density of the depicted velocity vectors. Nonetheless, there is no significant deviation between values obtained graphically and during CFD computations of the steady flow torques and jet angles.
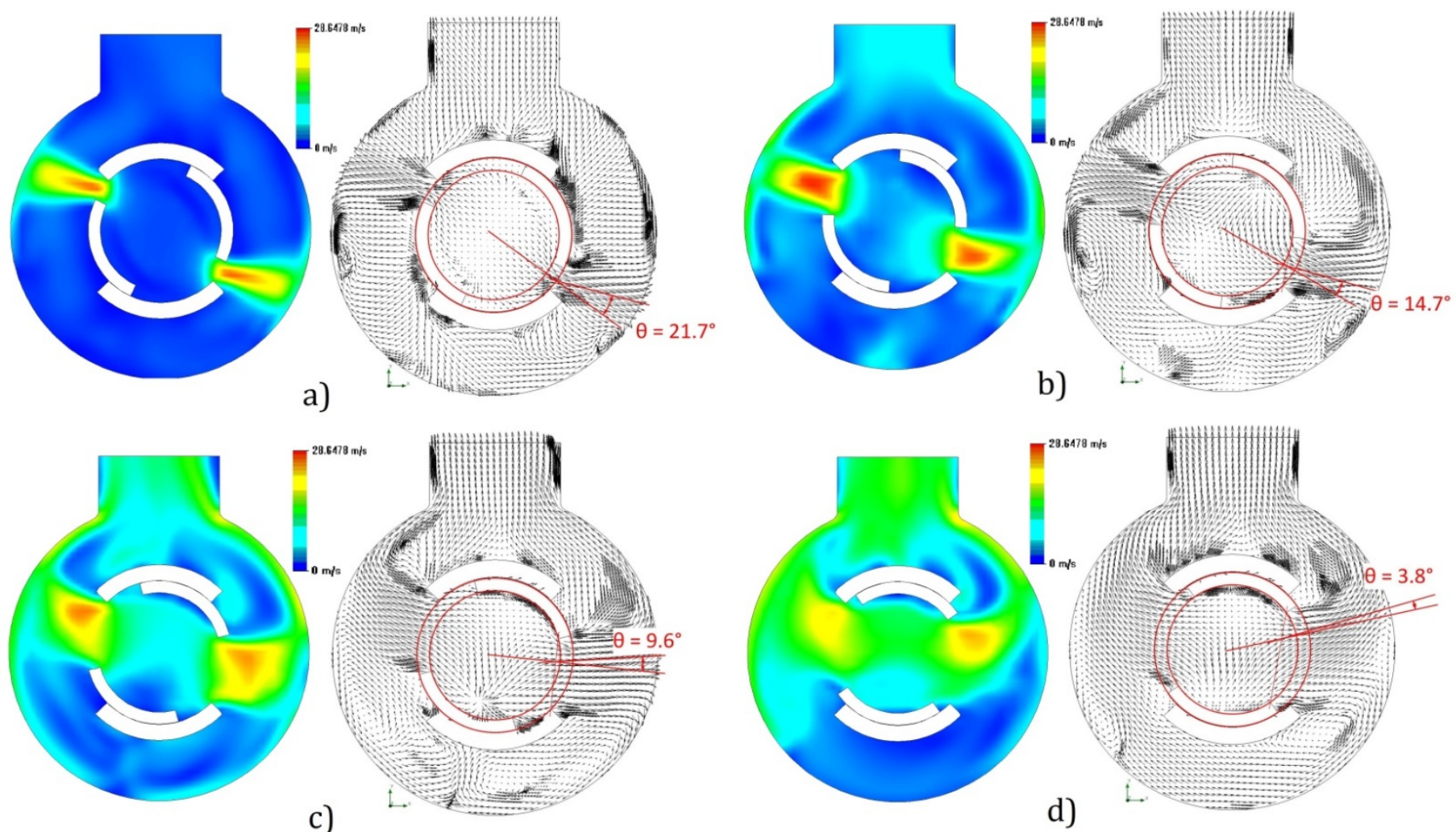

Fig. 17. Velocity distributions and velocity vector fields for different spool positions: a) $20^{\circ}$, b) $40^{\circ}$, c) $60^{\circ}$, d) $80^{\circ}$. Measurement of the jet angle graphically.

\section{Conclusions}

The flow modelling study conducted confirms the appropriateness of the structural approach to expanding the application of the directly controlled valves to the high flow rate operational domains. In particular, the proposed rotary arrangement of the throttling edges coupled with the hollow spool structure allows using less power demanding spool control without compromising the valve's hydraulic performance. 
Derived graphs of opening area, discharge coefficient, and jet angle constitute the complete definition of the functionality of the proposed valve design in the steady flow regimes. The CFD simulations verified the obtained theoretical model of the valve. Utilisation of this tool gave an understanding of the flow pattern in the fluid subdomain of the valve by visualisation of the flow paths.

Simulation based analysis shows small pressure losses in the suggested valve design along with low steady flow torques. The nonlinear opening area promises to improve controllability in actuator speed control. The developed valve design presents the feasible and sound structure of control valves for high flow rate power hydraulic systems. Its construction ensures improved controllability and maintainability due to the utilisation of a stepper motor and cartridge assembly. Furthermore, grouping four proposed valves in the independent metering arrangement also opens the opportunity to advance the efficiency of the fluid power systems by the implementation of energy regeneration and recuperation in the regulation of hydraulic motors. All in all noted factors prove the effectiveness of the proposed approach for designing of unconventional throttling orifices in flow control valves of high flow rate fluid power systems.

However, the presented geometrical model of the throttling parts can be further optimised in identified areas with the aim to achieve even smaller pressure drop values and consequently smaller flow torques on the spool. During selection of the spool driving rotary motor, it is recommended to evaluate dynamic properties of the valve assembly, conduct a more detailed study of transient flow regimes, and estimate effects of viscous and mechanical friction torques on the spool during position change. The operation of multiple rotary two-way valves in one arrangement is also of interest. Estimation of dynamics and efficiency of such modules develops further the independent metering approach in construction of hydraulic control systems.

\section{References}

Abdalla, M.O., Nagarajan, T., Hashim, F., 2011. NUMERICAL INVESTIGATION OF PRESSURE DROP IN HYDRAULIC SPOOL VALVE. Solid State Sci. Technol. 19, 48-60.

Amirante, R., Andrea Catalano, L., Tamburrano, P., 2014. The importance of a full 3D fluid dynamic analysis to evaluate the flow forces in a hydraulic directional proportional valve. Eng. Comput. 31, 898-922. doi:10.1108/EC-09-2012-0221

Amirante, R., Del Vescovo, G., Lippolis, a., 2006. Flow forces analysis of an open center hydraulic directional control valve sliding spool. Energy Convers. Manag. 47, 114-131. doi:10.1016/j.enconman.2005.03.010

Amirante, R., Distaso, E., Tamburrano, P., 2016. Sliding spool design for reducing the actuation forces in direct operated proportional directional valves: Experimental validation. ENERGY Convers. Manag. 119, 399-410. doi:10.1016/j.enconman.2016.04.068

Amirante, R., Moscatelli, P.G., Catalano, L. a., 2007. Evaluation of the flow forces on a direct (single stage) proportional valve by means of a computational fluid dynamic analysis. Energy Convers. Manag. 48, 942-953. doi:10.1016/j.enconman.2006.08.024

Ansaloni, G., Marani, P., Paoluzzi, R., 2008. Proportional Valve with Axial Flow and Rotational Metering, in: Proceedings of the 7th JFPS International Symposium on Fluid Power. Toyama, pp. 591-596. doi:10.5739/isfp.2008.591

Borghi, M., Cantore, G., Milani, M., Paoluzzi, R., 1998. Analysis of hydraulic components using computational fluid dynamics models. Proc. Inst. Mech. Eng. 212, 619-629. doi:10.1243/0954406981521583

Choi, K., Seo, J., Nam, Y., Kim, K.U., 2015. Energy-saving in excavators with application of independent metering valve. J. Mech. Sci. Technol. 29, 387-395. doi:10.1007/s12206-014-1245-5

Driest, E.R. Van, 1956. On Turbulent Flow Near a Wall. J. Aeronaut. Sci. (Institute Aeronaut. Sci. doi:10.2514/8.3713

Filho, J., De Negri, V., 2013. Model-Based Fault Detection for Hydraulic Servoproportional Valves, in: The 13th Scandinavian International Conference on Fluid Power, SICFP2013. Linköping, Sweden, pp. 389-398.

Herakovič, N., 2009. Flow-Force Analysis in a Hydraulic Sliding-Spool Valve. Strojarstvo 51, 555-564.

Ji, H., Cao, Y., Wang, Z., Wang, Y., 2011. Numerical analysis of temperature rise by throttling and deformation in spool valve. Proc. 2011 Int. Conf. Fluid Power Mechatronics, FPM 2011 752-756. doi:10.1109/FPM.2011.6045861

Johnston, N., Pan, M., 2015. Theoretical Studies of a Switched Inertance Hydraulic System in a Four-Port Valve Configuration, in: The Seventh Workshop on Digital Fluid Power.

Lam, C.K.G., Bremhorst, K., 1981. A Modified Form of the k- $\varepsilon$ Model for Predicting Wall Turbulence. J. Fluids Eng. $103,456$. doi:10.1115/1.3240815

Launder, B.E., Spalding, D.B., 1974. The numerical computation of turbulent flows. Comput. Methods Appl. Mech. Eng. 3, 269-289. doi:10.1016/0045-7825(74)90029-2

Lienhard, J.H., 1984. Velocity Coefficients For Free Jets From Sharp-Edged Orifices. J. Fluids Eng. $106,13$. doi:10.1115/1.3242391

Linjama, M., 2011. Digital Fluid Power - State of the Art, in: The 12th Scandinavian International Conference on Fluid Power. Tampere, Finland, pp. 331-354.

Lisowski, E., Czyzycki, W., Rajda, J., 2013. Three dimensional CFD analysis and experimental test of flow force acting on the spool of solenoid operated directional control valve. Energy Convers. Manag. 70, $220-229$. doi:10.1016/j.enconman.2013.02.016

Lisowski, E., Filo, G., 2016. CFD analysis of the characteristics of a proportional flow control valve with an innovative opening shape. Energy Convers. Manag. 123, 15-28. doi:10.1016/j.enconman.2016.06.025

Lisowski, E., Filo, G., Rajda, J., 2015. Pressure compensation using flow forces in a multi-section proportional directional control valve. Energy Convers. Manag. 103, 1052-1064. doi:10.1016/j.enconman.2015.07.038

Lisowski, E., Rajda, J., 2013. CFD analysis of pressure loss during flow by hydraulic directional control valve constructed from logic valves. Energy Convers. Manag. 65, 285-291. doi:10.1016/j.enconman.2012.08.015 
Merritt, H.E., 1968. Hydraulic Control Systems. John Wiley \& Sons, Inc., New York. doi:10.1115/1.3601167

Palumbo, A., Paoluzzi, R., Borghi, M., Milani, M., 1996. FORCES ON A HYDRAULIC VALVE SPOOL. Proc. JFPS Int. Symp. Fluid Power. doi:10.5739/isfp.1996.543

Pan, M., Johnston, N., Plummer, A., Kudzma, S., Hillis, A., 2013. Theoretical and experimental studies of a switched inertance hydraulic system. Proc. Inst. Mech. Eng. Part I J. Syst. Control Eng. 228, 12-25. doi:10.1177/0959651813500952

Pan, M., Johnston, N., Robertson, J., Plummer, A., Hillis, A., Yang, H., 2015. Experimental Investigation of a Switched Inertance Hydraulic System With a High-Speed Rotary Valve. J. Dyn. Syst. Meas. Control 137, 121003. doi:10.1115/1.4031325

Plummer, A., 2016. Electrohydraulic servovalves - past, present, and future, in: 10th International Fluid Power Conference, IFK2016. Dresden, Germany.

Posa, A., Oresta, P., Lippolis, A., 2013. Analysis of a directional hydraulic valve by a Direct Numerical Simulation using an immersed-boundary method. Energy Convers. Manag. 65, 497-506. doi:10.1016/j.enconman.2012.07.012

Product Information. CITGO A/W Hydraulic oils, 2012.

Rajda, J., Lisowski, E., 2013. Flow forces acting on the spool of directional control valve. Czas. Tech. Mech. Tech. Trans. Mech. 349-356.

Rannow, M.B., Tu, H.C., Wang, M., Li, P.Y., Chase, T.R., 2010. Optimal design of a high-speed on/off valve for a hydraulic hybrid vehicle application, in: Proceedings of the 7th International Fluid Power Conference. Aachen, Germany, pp. 114.

Reichert, M., 2010. Development of high-response piezo-servovalves for improved performance of electrohydraulic cylinder drives. Aachen University, Aachen, Germany.

Shenouda, A., 2006. Quasi-Static Hydraulic Control Systems and Energy Savings Potential Using Independent Metering Four-Valve Assembly Configuration. Dr. Philos. Thesis. Woodruff School of Mechanical Engineering, Georgia Institute of Technology.

Simic, M., Herakovic, N., 2015. Reduction of the flow forces in a small hydraulic seat valve as alternative approach to improve the valve characteristics. Energy Convers. Manag. 89, 708-718. doi:10.1016/j.enconman.2014.10.037

Sobachkin, A., Dumnov, G., 2013. Numerical Basis of CAD-Embedded CFD. NAFEMS World Congr. 2013 1-20.

SolidWorks, 2015. SolidWorks Flow Simulation.

SolidWorks, 2013a. Enhanced Turbulence Modeling in SolidWorks Flow Simulation.

SolidWorks, 2013b. Advanced Boundary Cartesian Meshing Technology in SolidWorks Flow Simulation.

Trancossi, M., 2011. An Overview of Scientific and Technical Literature on Coanda Effect Applied to Nozzles. SAE Tech. Pap. 1-13. doi:10.4271/2011-01-2591

Tu, H.C., Rannow, M.B., Van de Ven, J.D., Wang, M., Li, P.Y., Chase, T.R., 2007. High speed rotary pulse width modulated on/off valve, in: Proceedings of the International Mechanical Engineering Congress. Seattle, Washington, pp. 1-13. doi:10.1115/IMECE2007-42559

Tu, H.C., Rannow, M.B., Wang, M., Li, P.Y., Chase, T.R., Cheong, K.L., 2011. High-Speed 4-Way Rotary On/Off Valve for Virtually Variable Displacement Pump/Motor Applications. ASME 2011 Dyn. Syst. Control Conf. Bath/ASME Symp. Fluid Power Motion Control 1, 201-208. doi:10.1115/DSCC2011-6109

Tu, H.C., Rannow, M.B., Wang, M., Li, P.Y., Chase, T.R., Van de Ven, J.D., 2012. Design, Modeling, and Validation of a HighSpeed Rotary Pulse-Width-Modulation On/Off Hydraulic Valve. J. Dyn. Syst. Meas. Control $134,061002$. doi:10.1115/1.4006621

Wang, H., Gong, G., Zhou, H., Wang, W., 2016. Steady flow torques in a servo motor operated rotary directional control valve. Energy Convers. Manag. 112, 1-10. doi:10.1016/j.enconman.2015.11.054

Wang, M., Li, P.Y., 2009. Duty ratio control of a rotary pwm valve with periodic measurement error. Proc. Am. Control Conf. 5073-5078. doi:10.1109/ACC.2009.5160693

Wang, M., Tu, H., Rannow, M., Li, P., Chase, T., 2010. CFD analysis of a novel high speed rotary on/off valve. Proc. 6th FPNIPhD Symp. 283-294.

White, F., 1999. Fluid Mechanics, Fourth ed. ed. McGraw-Hill series in mechanical engineering.

Wilcox, D.C., 2006. Turbulence Modeling for CFD, Third edit. ed. DCW Industries, Inc.

Yang, H., Pan, M., 2015. Engineering research in fluid power: a review. J. Zhejiang Univ. - Sci. A Appl. Phys. Eng. 16, 427442. doi:10.1631/jzus.A1500042

Yang, Y., Guglielmino, E., Dai, J.S., Boaventura, T., Caldwell, D.G., 2010. Modeling of a novel 3-way rotary type electrohydraulic valve, in: 2010 IEEE International Conference on Information and Automation, ICIA 2010. Harbin, China, pp. 1463-1468. doi:10.1109/ICINFA.2010.5512286

Yu, J., Zhuang, J., Yu, D., 2015. State feedback integral control for a rotary direct drive servo valve using a Lyapunov function approach. ISA Trans. 54, 207-217. doi:10.1016/j.isatra.2014.08.006

Yu, J., Zhuang, J., Yu, D., 2014. Modeling and analysis of a rotary direct drive servovalve. Chinese J. Mech. Eng. 27, 10641074. doi:10.3901/CJME.2014.0725.127 